Open Access

\title{
Analyzing the gene expression profile of anaplastic histology Wilms' tumor with real-time polymerase chain reaction arrays
}

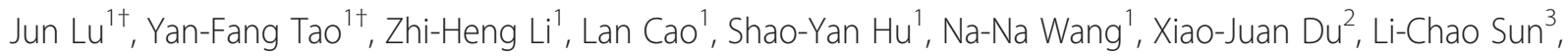
Wen-Li Zhao ${ }^{1}$, Pei-Fang Xiao ${ }^{1}$, Fang Fang ${ }^{1}$, Li-xiao Xu' ${ }^{1}$, Yan-Hong Li ${ }^{1}$, Gang Li ${ }^{1}$, He Zhao ${ }^{1}$, Jian Ni ${ }^{4}$, Jian Wang ${ }^{1}$, Xing Feng ${ }^{1 *}$ and Jian Pan ${ }^{1 *}$

\begin{abstract}
Background: Wilms' tumor (WT) is one of the most common malignant neoplasms of the urinary tract in children. Anaplastic histology (unfavorable histology) accounts for about 10\% of whole WTs, and it is the single most important histologic predictor of treatment response and survival in patients with WT; however, until now the molecular basis of this phenotype is not very clearly.

Methods: A real-time polymerase chain reaction (PCR) array was designed and tested. Next, the gene expression profile of pediatric anaplastic histology WT and normal adjacent tissues were analyzed. These expression data were anlyzed with Multi Experiment View (MEV) cluster software further. Datasets representing genes with altered expression profiles derived from cluster analyses were imported into the Ingenuity Pathway Analysis Tool (IPA).

Results: 88 real-time PCR primer pairs for quantitative gene expression analysis of key genes involved in pediatric anaplastic histology WT were designed and tested. The gene expression profile of pediatric anaplastic histology WT is significantly different from adjacent normal controls; we identified 15 genes that are up-regulated and 16 genes that are down-regulated in the former. To investigate biological interactions of these differently regulated genes, datasets representing genes with altered expression profiles were imported into the IPA for further analysis, which revealed three significant networks: Cancer, Hematological Disease, and Gene Expression, which included 27 focus molecules and a significance score of 43. The IPA analysis also grouped the differentially expressed genes into biological mechanisms related to Cell Death and Survival 1.15E ${ }^{-12}$, Cellular Development 2.84E ${ }^{-11}$, Cellular Growth

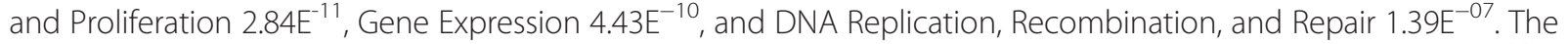
important upstream regulators of pediatric anaplastic histology WT were TP53 and TGF $\beta 1$ signaling $\left(P=1.15 E^{-14}\right.$ and $3.79 \mathrm{E}^{-13}$, respectively).

Conclusions: Our study demonstrates that the gene expression profile of pediatric anaplastic histology WT is significantly different from adjacent normal tissues with real-time PCR array. We identified some genes that are dysregulated in pediatric anaplastic histology WT for the first time, such as HDAC7, and IPA analysis showed the most important pathways for pediatric anaplastic histology WT are TP53 and TGF $\beta 1$ signaling. This work may provide new clues into the molecular mechanisms behind pediatric anaplastic histology WT.
\end{abstract}

Keywords: Pediatric anaplastic histology Wilms' tumor, Real-time PCR array, Ingenuity pathway analysis, HDAC7, TP53, TGF $\beta 1$

\footnotetext{
*Correspondence: xing_feng66@hotmail.com; panjian2008@163.com

${ }^{\dagger}$ Equal contributors

'Department of Hematology and Oncology, Children's Hospital of Soochow

University, Suzhou, China
Full list of author information is available at the end of the article

University, Suzhou, China
Full list of author information is available at the end of the article
}

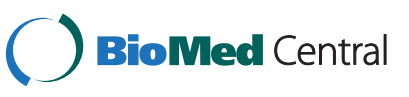

(c) 2015 Lu et al. This is an Open Access article distributed under the terms of the Creative Commons Attribution License (http://creativecommons.org/licenses/by/4.0), which permits unrestricted use, distribution, and reproduction in any medium, provided the original work is properly credited. The Creative Commons Public Domain Dedication waiver (http:// creativecommons.org/publicdomain/zero/1.0/) applies to the data made available in this article, unless otherwise stated. 


\section{Background}

The genetics of Wilms' tumor (WT), a pediatric malignancy of the kidney, is complex. This disease is named after Dr. Max Wilms, a German surgeon (1867-1918) who firstly described this disease [1,2]. WT is a malignant tumor containing metanephric blastema, epithelial derivatives and stromal. Characteristic of this tumor is the presence of glomeruli and abortive tubules surrounded by a spindle cell stroma. The stroma consists of striated muscle, cartilage, bone, adipose tissue, fibrous tissue composition [1-3]. Clinically, the tumor compresses the kidney parenchyma, inhibiting normal function. In most children, the causes of WT are unknown. Very rarely, children that develop WT have other specific conditions present at birth, mainly congenital malformations. Moreover, mutations in WT1 on chromosome $11 \mathrm{p} 13$ are observed in about $20 \%$ of WTs [4]. At least $50 \%$ of the wilm tumor patients with WT1 mutations also carry mutations in CTNNB1, which encoding a proto-oncogene beta-catenin [5-7]. Although until now this disease has been curable with good long-term survival, the combination of chemotherapy, surgery and radiotherapy always results in severe complications. Novel therapeutic strategies which can decrease treatment burden and improve outcome of high risk patients are still required.

About $10 \%$ of WTs presentd as anaplastic histology (unfavorable histology). Clinical study showed that anaplastic histology is an important histologic predictor of treatment response and survival in patients with WT; the overall survival rate for patients with favorable histology is higher than for those with anaplastic unfavorable histology [8]. For anaplasia there are two histologic criteria, both of which must be present for the diagnosis: the presence of multipolar polyploid mitotic figures with marked nuclear enlargement and hyperchromasia [9]. Mutations in the p53 gene consistent with changes on chromosome $17 \mathrm{p}$ have been associated with foci of anaplastic histology [10-12].

Histopathology reports showed that p53 mutations were present in eight of eleven anaplastic WTs, p53 alterations may provide a molecular marker for anaplastic WTs [12].

All of this phenomenon support the hypothesis that anaplasia tumor cells evolves from a subpopulation of WT cells that have acquired additional genetic lesions as a late event.

Studies have shown that anaplasia correlates best with responsiveness to therapy. It is most consistently associated with poor prognosis when it is diffusely distributed and when identified at advanced stages. An objective of the fifth National Wilms' Tumor Study (NWTS-5) was to evaluate the efficacy of treatment regimens for anaplastic histology Wilms' tumor (AH). A total of 2,596 patients with Wilms' tumor were enrolled onto NWTS-5 and the prognosis for patients with stage I AH is worse than that for patients with stage I FH(favorable histology). Four-year event-free survival (EFS) estimates for assessable patients with stage I AH $(n=29)$ were $69.5 \%$ (95\% CI, 46.9 to 84.0). In comparison, 4-year EFS estimates for patients with stage I favorable histology $(\mathrm{FH} ; \mathrm{n}=473)$ were $92.4 \%(95 \% \mathrm{CI}, 89.5$ to 94.5) $[9,13]$. Another report from china also showed that four-year overall survival rate for cases of favorable histology $(85.8 \%)$ was higher than for those with anaplastic histology (71.4\%; $\mathrm{p}=.028)$ [8]. Faria $\mathrm{P}$ and colleagues showed that the progress of Focal anaplasia (FA) is much better than diffuse anaplasia (DA) [14]. In 165 cases with anaplastic WT, Only three relapses and one death occurred among 39 cases with FA and 22 of 23 children with stage IV DA WT died of tumor. Anaplastic histology Wilms' tumors are more resistant to chemotherapy drugs which traditionally used in children with favorable histology WT. Despite this association with therapy resistance and poor prognosis, the molecular basis of this phenotype is still unclear.

Gene expression profiles of pediatric anaplastic histology WT are vague. However, several differentially expressed genes, e.g., MYCN, CTGF, TRIM22, CENPF, RARRES3, and $E Z H 2$, have been reported to be associated with WT progression [15]. CCAAT/enhancer binding protein beta (C/EBPB), is highly expressed in both primary relapsing tumors and metastatic tumors and it is a critical survival factor for WT cells [16]. Mutations in CTNNB1 (betacatenin) have also been detected in a subset of pediatric WTs. The comparison between WTs with and without CTNNB1 mutations revealed several target genes specifically deregulated in CTNNB1-mutated WTs [6].

Our previous work showed that a real-time polymerase chain reaction (PCR) array system is the ideal tool for analyzing the expression of a focused panel of genes $[17,18]$. The simplicity, flexibility, and convenience of standard SYBR green PCR detection methodology make the PCR array system accessible for routine use in any research laboratory [19]. Ingenuity Pathway Analysis (IPA) is one of several tools available to systems biology researchers and bioinformaticians in drug discovery and institutional research. IPA tool allows identification of biological networks, global functions, and functional pathways of a particular dataset. As previously mentioned, the gene expression profile of pediatric anaplastic histology WTs is still unclear. In this study, we analyzed dysregulated genes and pathways in pediatric anaplastic histology WTs with the powerful real-time PCR array platform.

\section{Results and discussion}

Designing the real-time PCR array

88 real-time PCR primer pairs for a quantitative gene expression analysis of key genes involved in pediatric 


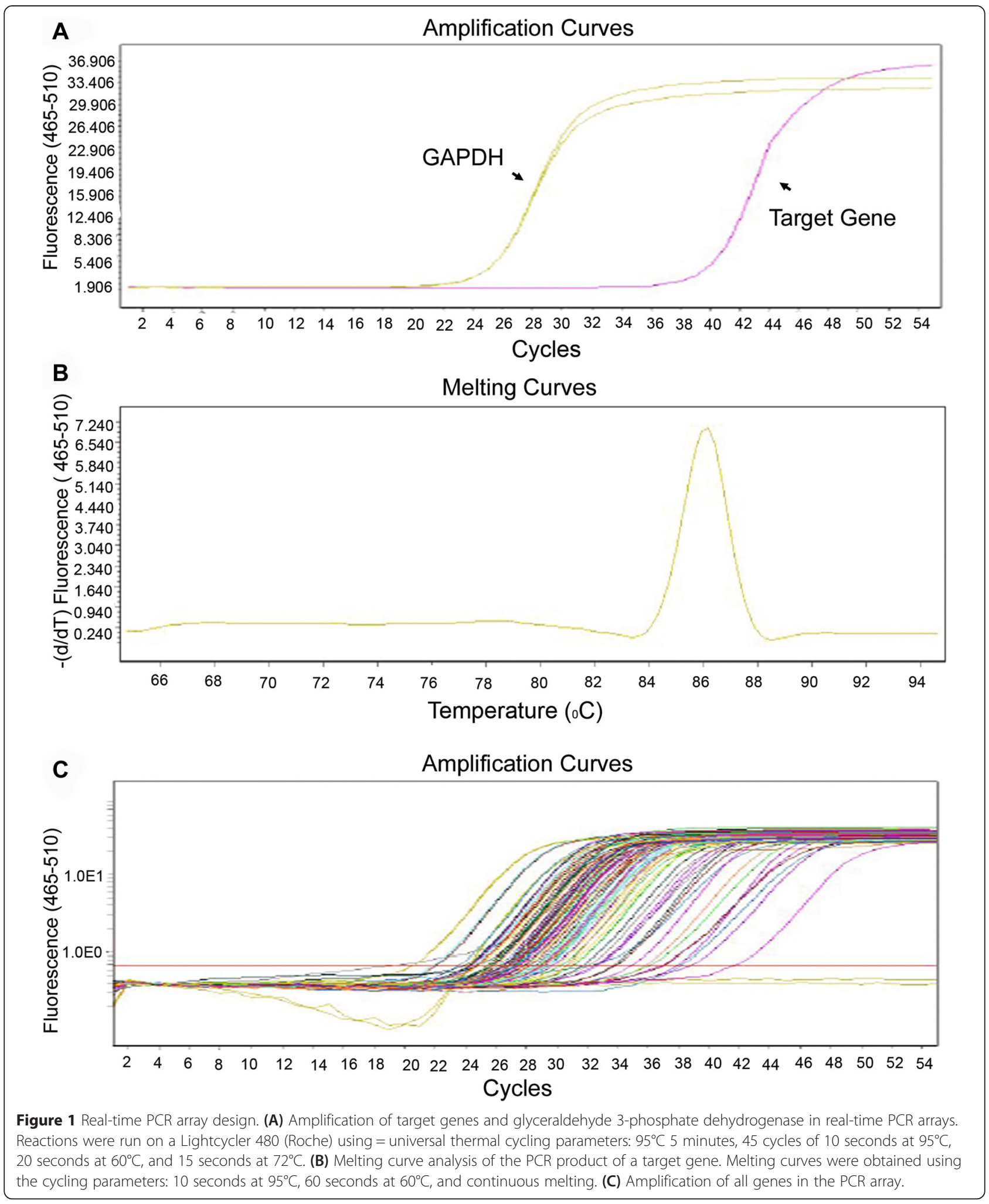

Wilms' tumor were designed and tested (Additional file 1) [20-22]. Briefly, we assayed the expression of 11 genes from the HOX family, 15 apoptosis related genes, eight histone deacetylases, seven chemokines,
13 tumor related genes and 17 important genes in cancer. Each gene was tested via expression and melting curve analysis to ensure that the primer was specific for the target gene (Figure 1). 


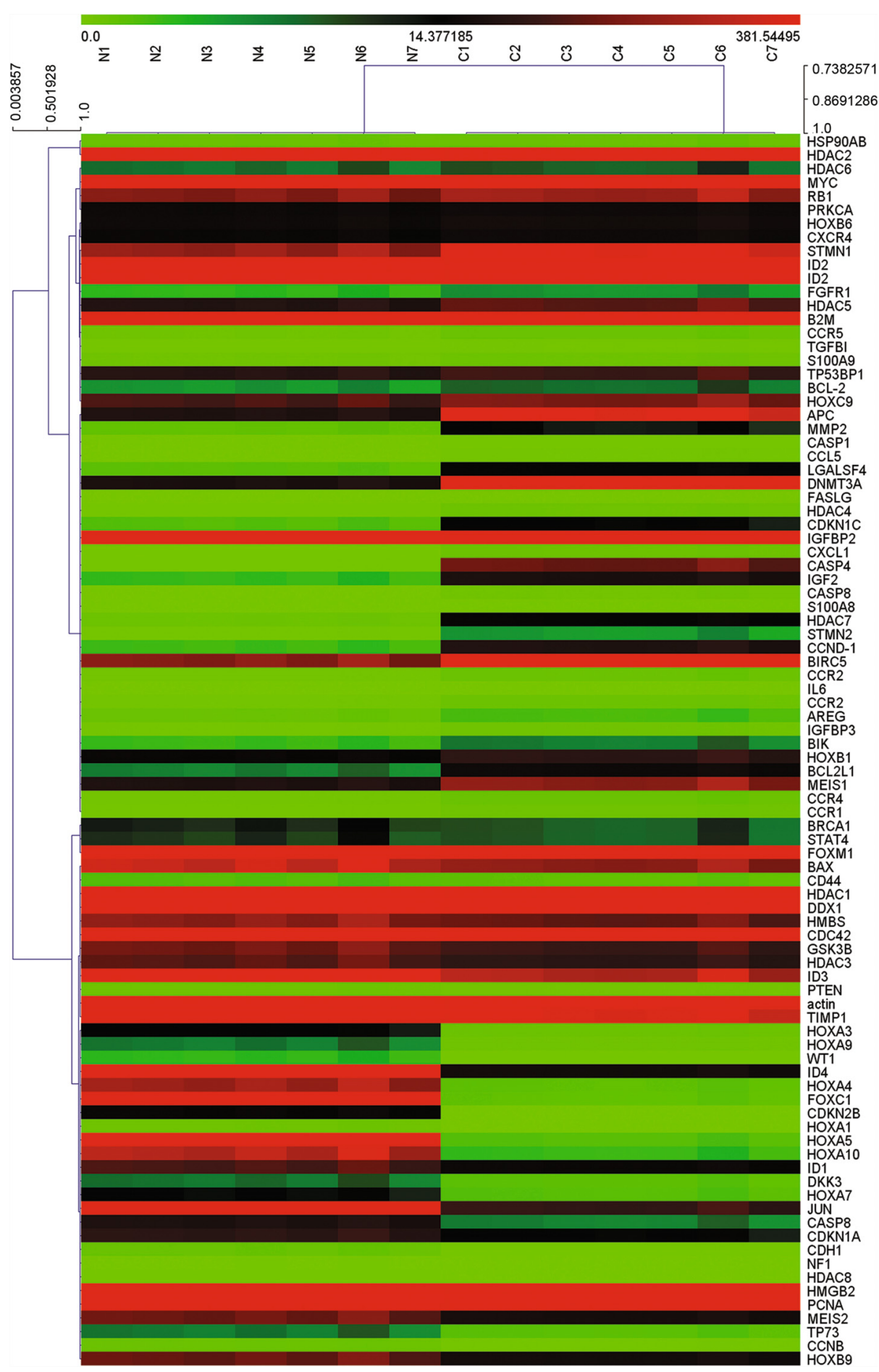

Figure 2 Expression and cluster analysis of pediatric anaplastic histology Wilms tumor and normal tissues adjacent to cancer. Cluster analysis of the data was performed with gene clustering from the real-time PCR arrays. For gene expression quantification, we used the comparative Ct method. First, gene expression levels for each sample were normalized to the expression level of the housekeeping gene encoding glyceraldehyde 3-phosphate dehydrogenase within a given sample $(-\Delta \mathrm{Ct})$. The relative expression of each gene was calculated using the equation: $10^{6}{ }^{*} \mathrm{Log}_{2}(-\Delta \mathrm{Ct})$. Gene expression between pediatric anaplastic histology Wilms tumor and normal tissues adjacent to cancer were analyzed using Multi Experiment View (MEV) cluster software. 
Table 1 Pediatric anaplastic histology Wilms' tumor patients' clinical features

\begin{tabular}{|c|c|c|c|c|c|c|c|}
\hline & Age (year) & Sex & $\mathrm{Hb}(\mathrm{g} / \mathrm{L})$ & WBC $\left(10^{9} / \mathrm{L}\right)$ & $\mathrm{RBC}\left(10^{12} / \mathrm{L}\right)$ & PLt $\left(10^{9} / \mathrm{L}\right)$ & Diagnosis \\
\hline 1 & 1 & M & 22.5 & 8.9 & 4.47 & 252 & Wilm's Tumor \\
\hline 2 & 3 & M & 100 & 16.9 & 3.8 & 326 & Wilm's Tumor \\
\hline 3 & 2.5 & $\mathrm{~F}$ & 115 & 7.4 & 4.47 & 231 & Wilm's Tumor \\
\hline 4 & 1.7 & $\mathrm{~F}$ & 94 & 16.7 & 3.32 & 599 & Wilm's Tumor \\
\hline 5 & 0.8 & M & 127 & 8.3 & 4.8 & 312 & Wilm's Tumor \\
\hline 6 & 2.7 & $\mathrm{~F}$ & 106 & 7.7 & 3.86 & 161 & Wilm's Tumor \\
\hline 7 & 2.9 & $\mathrm{~F}$ & 94 & 3.4 & 2.98 & 201 & Wilm's Tumor \\
\hline
\end{tabular}

Hb: Hemoglobin; WBC: White blood cells; RBC: Red blood cells; PLt: Platelet.

\section{Testing the real-time PCR array}

Using real-time PCR, we can easily and reliably analyze the expression of a focused panel of genes involved in pediatric Wilms' tumor. The average coefficient of variation $(\mathrm{CV})$ for the $\mathrm{CT}$ values generated from all PCR arrays was $0.73 \%$ with replicate measurements for CT values below 30 within 0.73 cycle average standard deviation, demonstrating good inter-run reproducibility.

\section{Expression profile analysis of pediatric anaplastic} histology WT and adjacent normal tissues

Gene expression profile of pediatric anaplastic histology WT and adjacent normal control samples was analyzed with our real-time PCR arrays (Figure 2A). Clinical information from seven anaplastic pediatric WT samples used is listed in Table 1. After obtaining original data, we analyzed expression data with Multi Experiment View (MEV) cluster software. The gene expression profile of pediatric anaplastic histology WT was significantly different from normal tissues adjacent to cancer, and comprised a set of genes that could be successfully clustered (Figure 3). Compared with normal controls, we identified 15 genes that were up-regulated and 16 genes that were down-regulated in pediatric anaplastic histology WT. The detailed expression of each up-regulated gene in pediatric anaplastic histology WT is presented in

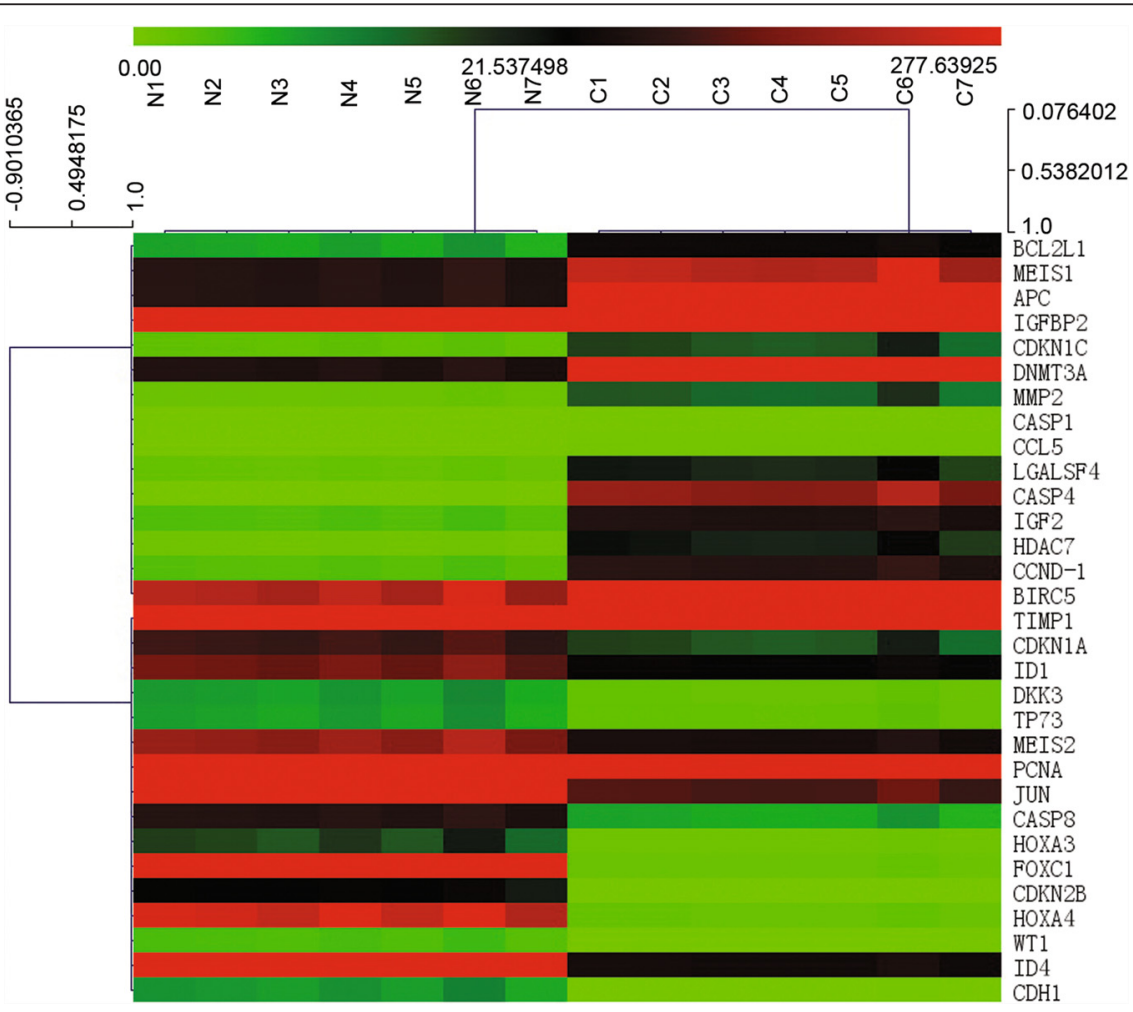

Figure 3 Cluster analysis of pediatric anaplastic histology Wilms' tumor and normal tissues adjacent to cancerous tissue. Thirty one genes were successfully clustered in pediatric anaplastic histology Wilms' tumor and normal tissues adjacent to cancerous tissue. 
Figure 4 and Table 2, while the expression of downregulated genes is presented in Figure 5 and Table 3. Figure 2 shows the 88 genes detected by PCR array can distinguish anaplastic Wilms tumor and adjacent normal tissues, Figure 3 shows that use a small group of different genes (fold change $>2.0$ ) can also distinguish anaplastic Wilms tumor and adjacent normal tissues.

Results showed that some of the dysregulated genes that we identified are consistent with previous other's reports, such as BIRC5, IGF2, and IGFBP2. BIRC5, also known as survivin, is expressed in virtually most of human tumors, but is undetectable or present at very low levels in most normal adult tissues. This tumor-specific expression of survivin is predominantly dictated at the level of transcription, as survivin gene expression may be globally deregulated in tumors in vivo. Immunohistochemical expression of survivin was analyzed in 59 cases of primary WT and in ten normal kidney specimens,

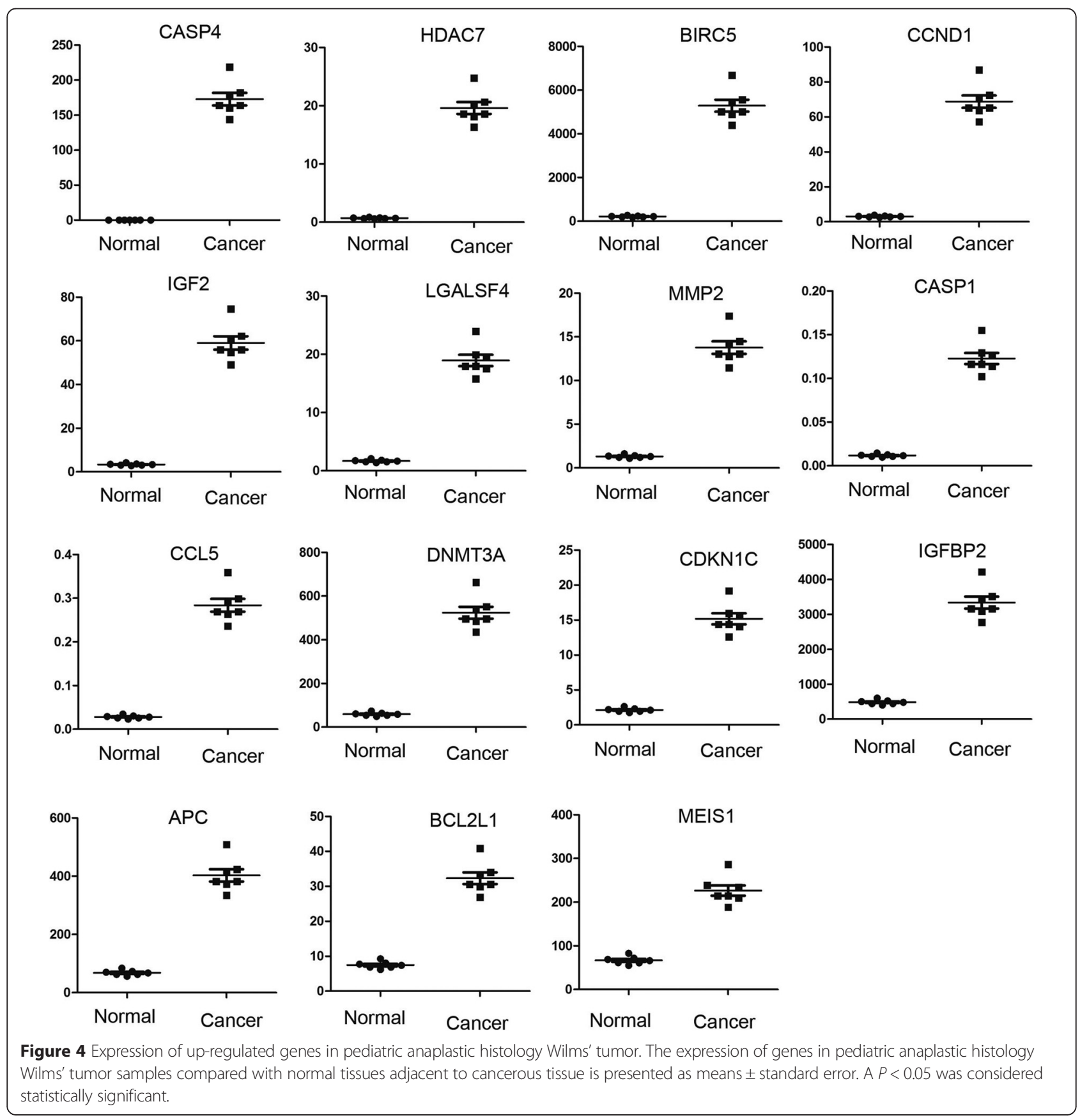


Table 2 Genes up-regulated in the pediatric Wilms' tumor compared with normal tissues adjacent to cancerous tissue

\begin{tabular}{lllllll}
\hline & Gene & Description & Control & WT & Fold change & P \\
\hline 1 & CASP4 & Caspase 4 & 0.145779 & 172.8901 & 1185.974 & 27.89349 \\
2 & HDAC7 & Histone deacetylase 7 & 0.703126 & 19.61264 & 24.3435 & 0.0011 \\
3 & BIRC5 & Baculoviral IAP repeat containing 5 & 217.2588 & 5288.839 & 0.0021 \\
4 & CCND1 & Cyclin D1 & 3.035334 & 68.77021 & 22.65655 & 0.0023 \\
5 & IGF2 & Insulin-like growth factor 2 & 3.39134 & 59.04372 & 17.41014 & 0.0025 \\
6 & LGALS4 & Lectin, galactoside-binding, soluble, 4 & 1.683957 & 18.94456 & 11.25002 & 0.0028 \\
7 & MMP2 & Matrix metallopeptidase 2 & 1.31208 & 13.77244 & 10.49664 & 0.0028 \\
8 & CASP1 & Caspase 1 & 0.011731 & 0.122743 & 10.46301 & 0.0031 \\
9 & CCL5 & Chemokine (C-C motif) ligand 5 & 0.0282 & 0.283951 & 10.06905 & 0.0031 \\
10 & DNMT3A & DNA methyltransferase 3 alpha & 59.37795 & 524.1049 & 8.826591 & 0.0033 \\
11 & CDKN1C & Cyclin-dependent kinase inhibitor 1C & 2.13148 & 15.17592 & 7.119897 & 0.0033 \\
12 & IGFBP2 & Insulin-like growth factor binding protein 2 & 485.0049 & 3335.557 & 6.877367 & 0.0034 \\
13 & APC & Adenomatous polyposis coli & 68.20736 & 402.7419 & 5.904669 & 0.0054 \\
14 & BCL2L1 & BCL2-like 1 & 7.47387 & 32.30559 & 4.322471 & 3.391342 \\
15 & MEIS1 & Meis homeobox 1 & 66.80367 & 226.5541 & 0.0059 \\
\hline
\end{tabular}

taken from the same patients, but distant from the tumor. Decreased cytoplasmic or nuclear overexpression of survivin may be related to a favorable WT prognosis [23]. Furthermore, treatment with YM155, a novel survivin inhibitor, resulted in inhibition of SK-NEP-1 proliferation, illustrating its potential as a therapeutic modality in WT [24].

Human insulin-like growth factor II (IGF2) is overexpressed and its imprinting is disrupted in many tumors, including WT. In WTs that demonstrate maintenance of imprinting of IGF2, IGF2-AS (the anti-sense version of IGF2) is also imprinted [25]. A pilot study indicated a significant relationship between loss of imprinting of IGF2 and family history as well as personal history of colorectal cancer, suggested that loss of IGF2 imprinting might be a valuable molecular marker of predicting an individual's risk for colon cancer [26]. Loss of imprinting of IGF2 results in a modest increase in IGF2 expression, and it is present in about $30 \%$ of patients with colorectal cancer. To investigate its role in intestinal tumorigenesis, a mouse model of IGF2 loss of imprinting was created by crossing female $\mathrm{H}_{1} 9^{+/-}$mice with male $\mathrm{Apc}^{+} / \mathrm{Min}$ mice. Mice with loss of imprinting developed twice as many intestinal tumors as did control littermates. Thus, altered maturation of non-neoplastic tissue may be one mechanism by which epigenetic changes increase cancer risk [27]. Mice with sustained mosaic, somatic ablation of WT1 and constitutional IGF2 up-regulation have been engineered, mimicking a subset of human tumors; mice with this combination of genetic alterations developed tumors at an early age. Mechanistically, increased IGF2 expression up-regulates ERK1/2 phosphorylation [28].
Insulin-like growth factors binding protein-2 (IGFBP-2) has been measured in plasma of children with WT and was shown to be significantly elevated relative to controls. Therefore, IGFBP-2 measurements might be valuable as a marker for monitoring this type of tumor, either as an adjunct to diagnosis or for tumor growth surveillance during therapy [29]. IGFBP2 overexpression has also been noted in other cancers, such as in ovarian malignant tissues and in the serum and cystic fluid of ovarian cancer patients. Moreover, IGFBP2 was significantly overexpressed in invasive serous ovarian carcinomas compared with borderline serous ovarian tumors and IGFBP2 has been shown to enhance the invasion capacity of ovarian cancer cells. Furthermore, plasma IGFBP-2 is elevated in patients with malignant adrenocortical tumors and the major factor affecting IGFBP-2 levels in these patients is tumor stage [30]. Blockade of IGFBP2 may thus constitute a viable strategy for targeted cancer therapy, including WT [31].

Our work also identified novel dysregulated genes in pediatric anaplastic histology WT. For instance, gene expression profiling showed that $H D A C 7$ is dysregulated in pediatric anaplastic histology WT [18]. HDAC7 is a crucial player in cancer cell proliferation, as knockdown of $H D A C 7$ results in significant $\mathrm{G}_{1} / \mathrm{S}$ arrest in different cancer cell lines. $H D A C 7$ silencing blocked cell cycle progression by suppressing c-Myc expression and increasing p21 and p27 protein levels [32]. Furthermore, acute lymphoblastic leukemia (ALL) samples showed higher expression levels of HDAC7 compared to normal bone marrow samples. HDAC7 expression levels higher than median values were also associated with a lower 5 -year event-free survival (EFS) in the overall group. 


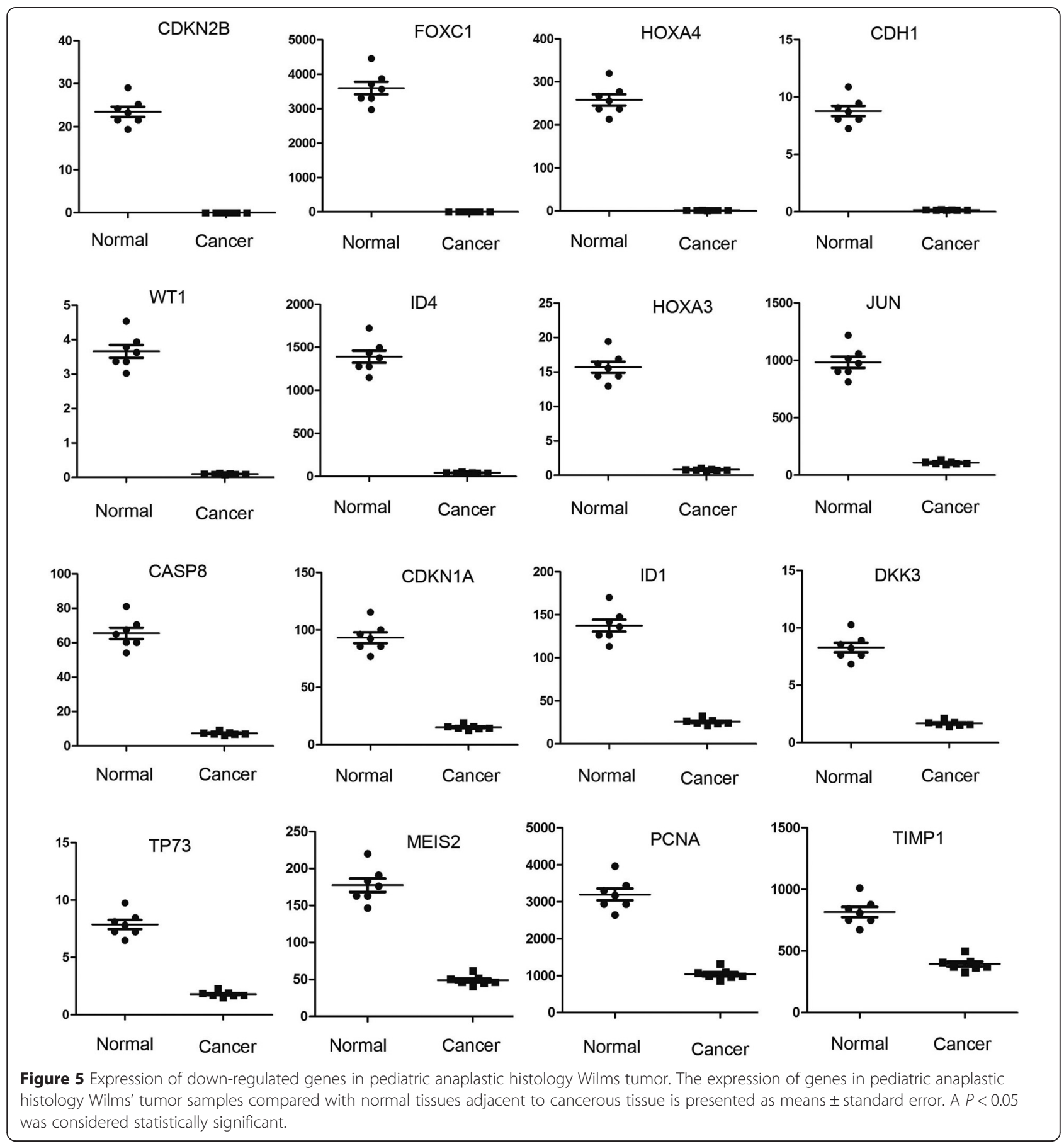

Moreover, higher expression of HDAC7 is associated with poor prognosis in childhood ALL and could be a promising therapeutic target for the treatment of refractory childhood ALL [33]. HDAC7 has also been implicated in pancreatic tumors; for instance, increased $H D A C 7$ expression discriminates pancreatic tumors from normal pancreas tissue [34]. Silencing of $H D A C 7$ in endothelial cells alters their morphology, migration, and capacity to form capillary tube-like structures in vitro but does not affect cell adhesion, proliferation, or apoptosis. In addition, $H D A C 7$ is a key modulator of endothelial cell migration and hence angiogenesis [35]. In other cancers, HDAC7 is up-regulated, such as in early human colon carcinogenesis in which it plays an important role in early carcinogenic events [36]. In chronic lymphocytic leukemia patients, $H D A C 7$ was a treatment-free survival independent predictor and poor prognosis was associated with $H D A C 7$ overexpression [37]. In the present study, 
Table 3 Genes down-regulated in the pediatric Wilms tumor compared with normal tissues adjacent to cancerous tissue

\begin{tabular}{|c|c|c|c|c|c|c|}
\hline & Gene & Description & Control & WT & Fold change & $\mathbf{P}$ \\
\hline 1 & CDKN2B & Cyclin-dependent kinase inhibitor 2B (p15) & 23.45552 & 0.002128 & -11022.3 & $<0.001$ \\
\hline 2 & FOXC1 & Forkhead box C1 & 3595.198 & 1.408063 & -2553.29 & 0.0011 \\
\hline 3 & HOXA4 & Homeobox A4 & 258.1124 & 1.562344 & -165.208 & 0.0011 \\
\hline 4 & $\mathrm{CDH} 1$ & Cadherin 1, type 1, E-cadherin & 8.779151 & 0.157531 & -55.7295 & 0.0012 \\
\hline 5 & WT1 & Wilms' tumor 1 & 3.66003 & 0.099698 & -36.7111 & 0.0013 \\
\hline 6 & ID4 & Inhibitor of DNA binding 4 & 1390.951 & 41.75022 & -33.316 & 0.0014 \\
\hline 7 & HOXA3 & Homeobox A3 & 15.69089 & 0.814345 & -19.2681 & 0.0017 \\
\hline 8 & JUN & Jun proto-oncogene & 983.5506 & 107.912 & -9.11437 & 0.0017 \\
\hline 9 & CASP8 & Caspase 8 & 65.42887 & 7.329485 & -8.9268 & 0.0021 \\
\hline 10 & CDKN1A & cyclin-dependent kinase inhibitor 1A (p21) & 93.174 & 15.17592 & -6.1396 & 0.0021 \\
\hline 11 & ID1 & Inhibitor of DNA binding 1 & 137.3636 & 25.70027 & -5.34483 & 0.0034 \\
\hline 12 & DKK3 & Dickkopf 3 homolog & 8.292778 & 1.686125 & -4.91825 & 0.0043 \\
\hline 13 & TP73 & Tumor protein p73 & 7.868963 & 1.807144 & -4.35436 & 0.0056 \\
\hline 14 & MEIS2 & Meis homeobox 2 & 177.5222 & 48.96611 & -3.62541 & 0.0061 \\
\hline 15 & PCNA & Proliferating cell nuclear antigen & 3195.565 & 1040.969 & -3.0698 & 0.0067 \\
\hline 16 & TIMP1 & TIMP metallopeptidase inhibitor 1 & 815.6778 & 394.4536 & -2.06787 & 0.0078 \\
\hline
\end{tabular}

we demonstrate for the first time that $H D A C 7$ is upregulated in anaplasia pediatric WT, suggesting that it may play an important role in the occurrence and development of this disease. As with the other cancers mentioned previously, $H D A C 7$ is a potential candidate therapeutic target for anaplasia WTs.

Ingenuity pathway analysis of the dysregulated genes in pediatric anaplastic histology WT

To investigate possible biological interactions of differently regulated genes, datasets representing genes with altered expression profiles derived from the real-time PCR array analyses were imported into the IPA tool. The list of differentially expressed genes analyzed by IPA revealed 12 significant networks (Additional file 2) and Figure 6A shows the top three networks identified by IPA: Cancer, Hematological Disease, and Gene Expression comprised 27 focus molecules and significance scores of 43 (Figure 6D). The score represents the probability that a collection of genes equal to or greater than the number in a network could be achieved by chance alone. A score of three indicates a $1 / 1,000$ chance that the focus genes are in a network not due to random chance. The IPA analysis also groups differentially expressed genes into biological mechanisms that are related to Cell Death and Survival $1.15 \mathrm{E}^{-12}$, Cellular Development 2.84E $\mathrm{E}^{-11}$, Cellular Growth and Proliferation $2.84 \mathrm{E}^{-11}$, Gene Expression $4.43 \mathrm{E}^{-10}$, and DNA Replication, Recombination, and Repair $1.39 \mathrm{E}^{-07}$ (Figure 6B). IPA analysis revealed that, in pediatric anaplastic histology WT, the important upstream regulators are p53 and TGF 1 (Figure 6C).
Tumor protein $\mathrm{p} 53$, also known as $\mathrm{p} 53$, is a protein that in humans is encoded by the TP53 gene. The p53 protein plays a crucial role in multicellular organisms, in which it regulates the cell cycle and, thus, functions as a tumor suppressor. Mutations in p53 frequently occur in WT [38-42]. Although a correlation between anaplasia and mutations in the p53 tumor suppressor gene have been previous identified in WT, the prognostic significance of p53 in WT remains largely unresolved. Statistical analyses have revealed significant correlations between p53 expression and anaplasia and survival. Therefore, the TP53 gene may be of prognostic relevance with respect to poor outcome when present in WT unfavorable histology [43]. In another study, TP53 mutations were present in 8 of 11 anaplastic WTs. Thus, TP53 alterations act as a molecular marker for anaplastic WTs [12].

TGF $\beta 1$ is a polypeptide member of the transforming growth factor beta superfamily of cytokines. It is a secreted protein that performs many cellular functions, including controlling cell growth, proliferation, differentiation, and apoptosis [44]. Expression of TGF 1 in WT is associated with disease progression [45]: immunohistochemistry was used to examine TGF $\beta 1$ expression in 51 primary tumors and 17 invasive/metastatic tumors and the positive expression rate was $50.98 \%(26 / 51)$ and $82.35 \%(14 / 17)$, respectively. Furthermore, positive expression of TGF $\beta 1$ in WT correlated with tumor invasion and disease progression, which might be useful for identifying patients at high risk of unfavorable outcomes [45]. To date, the possible 


\section{A} Top Networks

ID Associated Network Functions

Cancer, Hematological Disease, Gene Expression

Cellular Development, Embryonic Development, Cancer

Cellular Development, Embryonic Development, Cancer
Connective Tissue Development and Function, Embryonic Development, Nervous System Development and Function

B

Molecular and Cellular Functions

Cell Death and Survival

Cellular Development

Cellular Growth and Proliferation

Gene Expression

DNA Replication, Recombination, and Repair

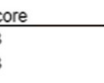

C Upstream Regulator

\begin{tabular}{lcl} 
& & Activation \\
\hline TP53 (includes EG:22059) & $1.15 E-14$ & Inhibited \\
phorbol myristate acetate & $2.94 \mathrm{E}-14$ & \\
EGF & $2.27 \mathrm{E}-13$ & \\
TGFB1 & $3.79 \mathrm{E}-13$ & \\
Tgf beta & $9.50 \mathrm{E}-13$
\end{tabular}

D

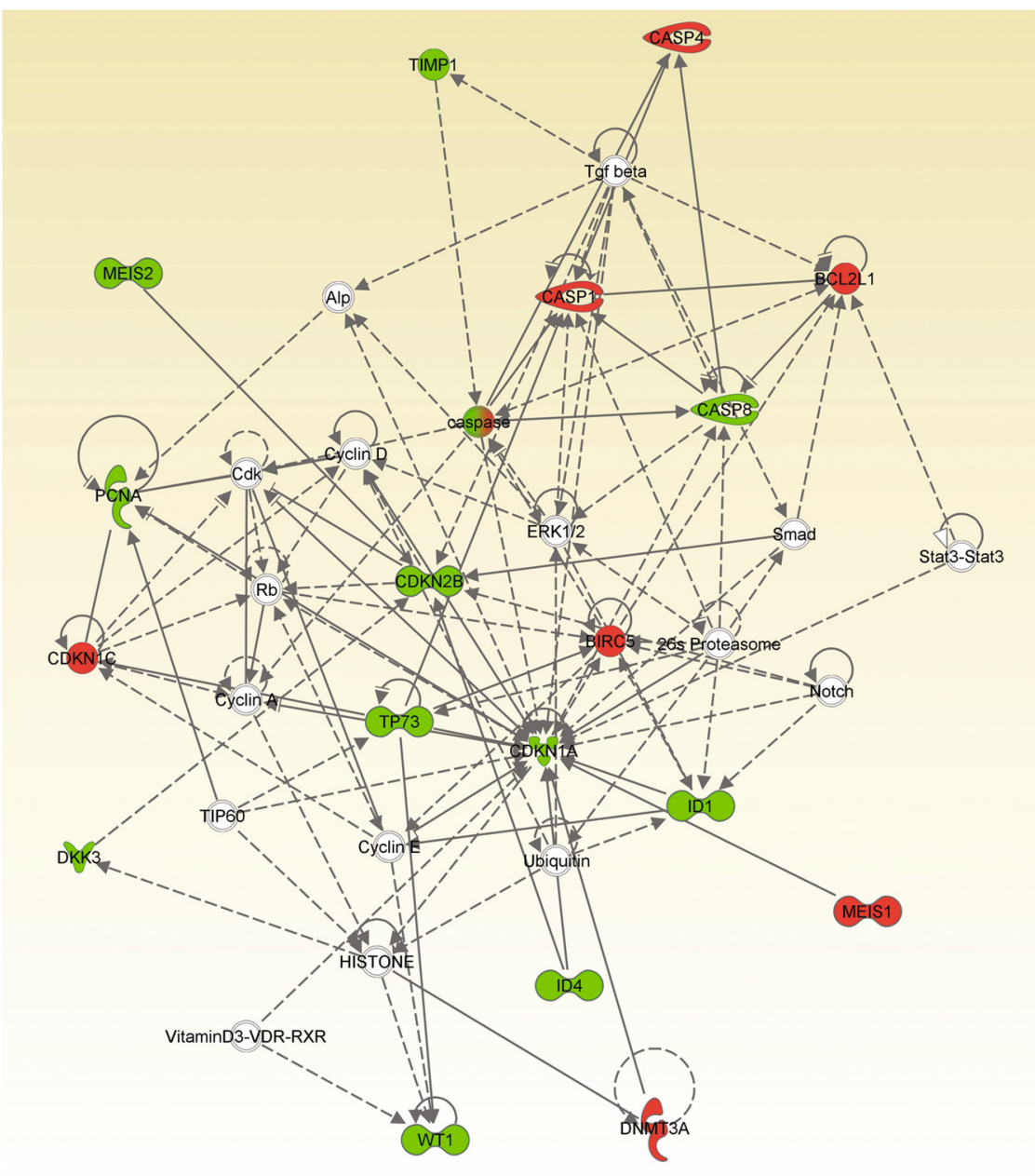

(9) 2000-2012 Ingenuity Systems, Inc. All rights reserved

Figure 6 (See legend on next page.) 
(See figure on previous page.)

Figure 6 Ingenuity Pathways Analysis summary. (A) A list of the top two networks with their respective scores obtained from the Ingenuity Pathway Analysis (IPA). (B) A list of molecular and cellular functions with their respective scores obtained from the IPA. (C) Upstream regulator list that includes TP53 and TGF 31 . IPA analysis showed in pediatric anaplastic histology Wilms' tumor the important upstream regulators are TP53 and TGF $\beta 1$ signaling. (D) Most highly rated network in the IPA analysis. The genes that are shaded were determined to be significant based on statistical analysis. The solid line represents a direct interaction between the two gene products and the dotted line indicates an indirect interaction.

regulation of TP53 and TGF $\beta 1$ signaling in pediatric anaplastic histology WT has not been reported. Future studies should focus on the molecular mechanism of TP53 and TGF 1 in WT.

\section{Conclusions}

The present study demonstrates that the gene expression profile of pediatric anaplastic histology WT is significantly different from normal controls; there are 15 genes that are up-regulated and 16 genes that are downregulated in pediatric anaplastic histology WT. We identified several novel genes that are dysregulated in pediatric anaplastic histology WT, such as HDAC7. IPA analysis showed the two most important pathways involved in pediatric anaplastic histology WT are TP53 and TGF $\beta 1$ signaling. This work may provide new clues into the molecular mechanisms behind pediatric anaplastic histology WT.

\section{Methods}

\section{Patients and samples}

Biopsy specimens were obtained from 7 patients with pediatric anaplastic histology wilm's tumor, who presented at the Department of Hematology and Oncology, Children's Hospital of Soochow University between 2010 and 2012. Ethical approval was provided by the Children's Hospital of Soochow University Ethics Committee (No.SUEC2010-031), and informed consent was obtained from the parents or guardians.

Pathology slides and institutional pathology reports were reviewed by the study pathologists. The designation of anaplasia was applied to tumors with cells having major diameters at least three times those of adjacent cells, increased chromatin content (hyperchromaticity) and the presence of atypical polyploid mitotic figures.

\section{Real-time PCR array analysis expression profile of pediatric anaplastic histology WT and adjacent normal tissues}

Most of the primers were from a database of Real-time primers, Center for Medical Genetics (http://medgen.ugent.be/CMGG/). The rest of primers were designed using the online program Primer 3 (www.fokker.wi.mit.edu/primer3/input.htm). Primer selection parameters were set to primer size: $20-26$ nts; primer melting temperature: 60 to $64^{\circ} \mathrm{C}$; GC clamp: 1 ; and product size range: generally $120-240 \mathrm{bp}$ but down to $100 \mathrm{bp}$ if no appropriate primers could be identified. Primers were ordered from Invitrogen. (Genes and sequence of the primers was presented in Additional file 1). Samples from each group were submerged in $2 \mathrm{ml}$ Trizol (Invitrogen Co., NY, USA) for RNA extraction, stored at $-80^{\circ} \mathrm{C}$ until further processed. cDNA synthesis was performed on 4 ug of RNA in a 10 ul sample volume using SuperScript II reverse transcriptase (Invitrogen Co., NY, USA) as recommended by the manufacturer. Real-time PCR array analysis was according to the MIQE Guidelines and performed in a total volume of $20 \mu \mathrm{l}$ including $1 \mu \mathrm{l}$ of cDNA, primers $(0.2 \mathrm{mM}$ each) and $10 \mu \mathrm{l}$ of SYBR Green mix (Roche). Reactions were run on an Lightcycler 480 (Roche) using universal thermal cycling parameters $\left(95^{\circ} \mathrm{C}\right.$ for $5 \mathrm{~min}, 45$ cycles of $10 \mathrm{sec}$ at $95^{\circ} \mathrm{C}$, $20 \mathrm{sec}$ at $60^{\circ} \mathrm{C}$ and $15 \mathrm{sec}$ at $72^{\circ} \mathrm{C}$; followed by a melting curve: $10 \mathrm{sec}$ at $95^{\circ} \mathrm{C}, 60 \mathrm{sec}$ at $60^{\circ} \mathrm{C}$ and continued melting). The results were obtained using the sequence detection software of the Lightcycler 480 and analyzed using Microsoft Excel. For quality control purposes, melting curves were acquired for all samples. The comparative $\mathrm{Ct}$ method was used to quantify gene expression. The target gene expression level was normalized to expression of the housekeeping gene glyceraldehyde 3-phosphate dehydrogenase (GAPDH) within the same sample $(-\Delta \mathrm{Ct})$, the relative expression of each gene was calculated with $10^{6}$ *Log2 $(-\Delta \mathrm{Ct})$. Statistical significance of the gene expression difference between the AML and the control samples was calculated with the $T$-test using SPSS 11.5 software and then the relative expression of each gene was calculated using $\log 2(-\Delta \mathrm{Ct})$.

\section{Ingenuity pathway analysis (IPA)}

Our datasets representing genes with altered expression profile derived from array analyses, 31 different genes (fold change $>2.0$ ) were imported into the Ingenuity Pathway Analysis Tool (IPA Tool; Ingenuity H Systems, Redwood City, CA, USA; http://www.ingenuity.com).

IPA analysis was introduced before [24]. IPA Tool allows the identification of biological networks, global functions and functional pathways of a particular dataset.

\section{Statistical analysis}

SPSS v11.5 (SPSS Inc., Chicago, IL) was used for statistical analysis. For gene expression quantification, we 
used the comparative Ct method. In our PCR array analysis three replicates of each gene were analyzed. First, gene expression levels for each sample were normalized to the expression level of the housekeeping gene encoding Glyceraldehydes 3-phosphate dehydrogenase (GAPDH) within a given sample $(-\Delta \mathrm{Ct})$; the relative expression of each gene was calculated with $10^{6}{ }^{*} \log _{2}(-\Delta \mathrm{Ct})$. The expression of the pediatric anaplastic histology wilm's tumor samples compared to the control samples was presented average $\pm \mathrm{SE}$. A $p<0.05$ was considered statistically significant.

\section{Additional files}

Additional file 1: Genes and PCR primers of Real-time PCR array.

Additional file 2: Summary of IPA analysis.

\section{Abbreviations}

WT: Wilms' Tumor; PCR: Polymerase chain reaction; IPA: Ingenuity pathway analysis; MEV: Multi experiment view; CV: Coefficient of variation; IGF2: Human insulin-like growth factor II; ALL: Acute lymphoblastic leukemia.

\section{Competing interests}

The authors declare that they have no competing interests.

\section{Authors' contributions}

PJ designed and directed the study. $L$ and TYF finished the experiments of Real-time PCR array. LZH and WNN designed the primer of PCR. ZWL and CL collected the tumor sample. HSY and XPF collected the clinical information of samples. DXJ and SLC supported the design of real-time PCR array. XLX, FF, LG and LYH drafted this manuscript. WJ, FX and NJ participated in study design and coordination, data analysis and interpretation and drafted the manuscript. All authors read and approved the final manuscript.

\section{Acknowledgements}

This work was supported by grants from the National Key Basic Research Program No. 2010CB933902, grants from key medical subjects of Jiangsu province (XK201120), Innovative team of Jiangsu Province (L201114, L201126), Special clinical medical science and technology of Jiangsu province (BL2012050, BL2013014), Key Laboratory of Suzhou (SZS201108, SZS201307), Science Foundation of suzhou (SYS201247), National Natural Science Foundation $(81100371,81370627,81300423,81272143)$. Natural Science Foundation of Jiangsu Province No. BK2011308, Universities Natural Science Foundation of Jiangsu Province No. 11KJB320014 and Talent's subsidy project in science and education of department of public health of Suzhou City No. SWKQ1020. Major scientific and technological special project for "significant new drugs creation" No. 2012ZX09103301-040.

\section{Author details}

'Department of Hematology and Oncology, Children's Hospital of Soochow University, Suzhou, China. ${ }^{2}$ Department of Gastroenterology, the 5th Hospital of Chinese PLA, Yin chuan, China. ${ }^{3}$ Department of Cell and Molecular Biology, Cancer Institute (Hospital), Chinese Academy of Medical Sciences, Peking Union Medical College, Beijing, China. ${ }^{4}$ Translational Research Center, Second Hospital, The Second Clinical School, Nanjing Medical University, Nanjing, China.

Received: 28 April 2014 Accepted: 12 April 2015

Published online: 20 April 2015

\section{References}

1. Al-Hussain T, Ali A, Akhtar M. Wilms tumor: an update. Adv Anat Pathol. 2014;21(3):166-73.

2. Tongaonkar HB, Qureshi SS, Kurkure PA, Muckaden MA, Arora B, Yuvaraja TB. Wilms' tumor: An update. Indian J Urol. 2007;23(4):458-66.
3. Cook A, Farhat W, Khoury A. Update on Wilms' tumor in children. J Med Liban. 2005;53(2):85-90.

4. Ruteshouser EC, Robinson SM, Huff V. Wilms tumor genetics: mutations in WT1, WTX, and CTNNB1 account for only about one-third of tumors. Genes Chromosomes Cancer. 2008;47(6):461-70.

5. Cardoso LC, De Souza KR, De ORAH, Andrade RC, Britto Jr AC, De Lima MA et al. WT1, WTX and CTNNB1 mutation analysis in 43 patients with sporadic Wilms' tumor. Oncol Rep. 2013;29(1):315-20.

6. Corbin M, de Reynies A, Rickman DS, Berrebi D, Boccon-Gibod L, CohenGogo S, et al. WNT/beta-catenin pathway activation in Wilms tumors: a unifying mechanism with multiple entries? Genes Chromosomes Cancer. 2009;48(9):816-27.

7. Fukuzawa R, Anaka MR, Weeks RJ, Morison IM, Reeve AE. Canonical WNT signalling determines lineage specificity in Wilms tumour. Oncogene. 2009;28(8):1063-75.

8. Yao W, Li K, Xiao X, Gao J, Dong K, Lv Z. Outcomes of Wilms' tumor in eastern China: 10 years of experience at a single center. J Investig Surg. 2012;25(3):181-5.

9. Graf N, van Tinteren H, Bergeron C, Pein F, van den Heuvel-Eibrink MM, Sandstedt B, et al. Characteristics and outcome of stage II and III nonanaplastic Wilms' tumour treated according to the SIOP trial and study 93-01. Eur J Cancer. 2012;48(17):3240-8.

10. Guertl B, Ratschek M, Harms D, Jaenig U, Leuschner I, Poremba C, et al. Clonality and loss of heterozygosity of WT genes are early events in the pathogenesis of nephroblastomas. Hum Pathol. 2003;34(3):278-81.

11. Lahoti C, Thorner P, Malkin D, Yeger H. Immunohistochemical detection of p53 in Wilms' tumors correlates with unfavorable outcome. Am J Pathol. 1996;148(5):1577-89.

12. Bardeesy N, Falkoff D, Petruzzi MJ, Nowak N, Zabel B, Adam M, et al. Anaplastic Wilms' tumour, a subtype displaying poor prognosis, harbours p53 gene mutations. Nat Genet. 1994;7(1):91-7.

13. Dome JS, Cotton CA, Perlman EJ, Breslow NE, Kalapurakal JA, Ritchey ML, et al. Treatment of anaplastic histology Wilms' tumor: results from the fifth National Wilms' Tumor Study. J Clin Oncol. 2006;24(15):2352-8.

14. Faria P, Beckwith JB, Mishra K, Zuppan C, Weeks DA, Breslow N, et al. Focal versus diffuse anaplasia in Wilms tumor-new definitions with prognostic significance: a report from the National Wilms Tumor Study Group. Am J Surg Pathol. 1996;20(8):909-20.

15. Zirn B, Hartmann O, Samans B, Krause M, Wittmann S, Mertens F, et al. Expression profiling of Wilms tumors reveals new candidate genes for different clinical parameters. Int J Canc. 2006;1 18(8):1954-62.

16. Li W, Kessler P, Yeger H, Alami J, Reeve AE, Heathcott R, et al. A gene expression signature for relapse of primary wilms tumors. Cancer Res. 2005;65(7):2592-601.

17. Tao YF, Pang L, Du XJ, Sun LC, Hu SY, Lu J, et al. Differential mRNA expression levels of human histone-modifying enzymes in normal karyotype B cell pediatric acute lymphoblastic leukemia. Int J Mol Sci. 2013;14(2):3376-94.

18. Yan-Fang T, Dong W, Li P, Wen-Li Z, Jun L, Na W, et al. Analyzing the gene expression profile of pediatric acute myeloid leukemia with real-time PCR arrays. Cancer Cell Int. 2012;12(1):40.

19. Liu F, Kuo WP, Jenssen TK, Hovig E. Performance comparison of multiple microarray platforms for gene expression profiling. Methods Mol Biol. 2012;802:141-55

20. Maturu P, Overwijk WW, Hicks J, Ekmekcioglu S, Grimm EA, Huff V. Characterization of the inflammatory microenvironment and identification of potential therapeutic targets in wilms tumors. Transl Oncol. 2014;7(4):484-92.

21. Shukrun R, Pode Shakked N, Dekel B. Targeted therapy aimed at cancer stem cells: Wilms' tumor as an example. Pediatr Nephrol. 2014;29(5):815-23. quiz 821.

22. Hamilton TE, Green DM, Perlman EJ, Argani P, Grundy P, Ritchey ML, et al. Bilateral Wilms' tumor with anaplasia: lessons from the National Wilms Tumor Study. J Pediatr Surg. 2006;41(10):1641-4.

23. Basta-Jovanovic G, Radojevic-Skodric S, Brasanac D, Djuricic S, Milasin J, Bogdanovic $L$, et al. Prognostic value of survivin expression in Wilms tumor. J BUON. 2012;17(1):168-73.

24. Tao YF, Lu J, Du XJ, Sun LC, Zhao X, Peng L, et al. Survivin selective inhibitor YM155 induce apoptosis in SK-NEP-1 Wilms tumor cells. BMC Cancer. 2012;12:619

25. Vu TH, Chuyen NV, Li T, Hoffman AR. Loss of imprinting of IGF2 sense and antisense transcripts in Wilms' tumor. Cancer Res. 2003;63(8):1900-5. 
26. Cui H. Loss of imprinting of IGF2 as an epigenetic marker for the risk of human cancer. Dis Markers. 2007;23(1-2):105-12.

27. Sakatani T, Kaneda A, lacobuzio-Donahue CA, Carter MG, de Boom WS, Okano $\mathrm{H}$, et al. Loss of imprinting of lgf2 alters intestinal maturation and tumorigenesis in mice. Science. 2005;307(5717):1976-8.

28. Hu Q, Gao F, Tian W, Ruteshouser EC, Wang Y, Lazar A, et al. Wt1 ablation and Igf2 upregulation in mice result in Wilms tumors with elevated ERK1/2 phosphorylation. J Clin Invest. 2011;121(1):174-83.

29. Zumkeller W, Schwander J, Mitchell CD, Morrell DJ, Schofield PN, Preece MA. Insulin-like growth factor (IGF)-I, -II and IGF binding protein-2 (IGFBP-2) in the plasma of children with Wilms' tumour. Eur J Cancer. 1993;29A(14):1973-7.

30. Boulle N, Baudin E, Gicquel C, Logie A, Bertherat J, Penfornis A, et al. Evaluation of plasma insulin-like growth factor binding protein-2 as a marker for adrenocortical tumors. Eur J Endocrinol. 2001:144(1):29-36.

31. Lee EJ, Mircean C, Shmulevich I, Wang H, Liu J, Niemisto A, et al. Insulin-like growth factor binding protein 2 promotes ovarian cancer cell invasion. Mol Cancer. 2005:4(1):7.

32. Zhu C, Chen Q, Xie Z, Ai J, Tong L, Ding J, et al. The role of histone deacetylase 7 (HDAC7) in cancer cell proliferation: regulation on c-Myc. J Mol Med (Berl). 2011;89(3):279-89.

33. Moreno DA, Scrideli CA, Cortez MA, de Paula QR, Valera ET, da Silva SV, et al. Differential expression of HDAC3, HDAC7 and HDAC9 is associated with prognosis and survival in childhood acute lymphoblastic leukaemia. $\mathrm{Br} J$ Haematol. 2010;150(6):665-73.

34. Ouaissi M, Sielezneff I, Silvestre R, Sastre B, Bernard JP, Lafontaine JS, et al. High histone deacetylase 7 (HDAC7) expression is significantly associated with adenocarcinomas of the pancreas. Ann Surg Oncol. 2008;15(8):2318-28.

35. Mottet D, Bellahcene A, Pirotte S, Waltregny D, Deroanne C, Lamour V, et al. Histone deacetylase 7 silencing alters endothelial cell migration, a key step in angiogenesis. Circ Res. 2007;101(12):1237-46.

36. Stypula-Cyrus Y, Damania D, Kunte DP, Cruz MD, Subramanian H, Roy HK, et al. HDAC up-regulation in early colon field carcinogenesis is involved in cell tumorigenicity through regulation of chromatin structure. PLoS One. 2013;8(5):e64600

37. Van Damme M, Crompot E, Meuleman N, Mineur P, Bron D, Lagneaux L, et al. HDAC isoenzyme expression is deregulated in chronic lymphocytic leukemia B-cells and has a complex prognostic significance. Epigenetics. 2012;7(12):1403-12.

38. Hsueh C, Wang H, Gonzalez-Crussi F, Lin JN, Hung IJ, Yang CP, et al. Infrequent p53 gene mutations and lack of p53 protein expression in clear cell sarcoma of the kidney: immunohistochemical study and mutation analysis of p53 in renal tumors of unfavorable prognosis. Mod Pathol. 2002;15(6):606-10.

39. Gafanovich A, Ramu N, Krichevsky S, Pe'er J, Amir G, Ben-Yehuda D. Microsatellite instability and p53 mutations in pediatric secondary malignant neoplasms. Cancer. 1999:85(2):504-10.

40. Kusafuka T, Fukuzawa M, Oue T, Komoto Y, Yoneda A, Okada A. Mutation analysis of p53 gene in childhood malignant solid tumors. J Pediatr Surg. 1997;32(8):1175-80.

41. Takeuchi S, Bartram CR, Ludwig R, Royer-Pokora B, Schneider S, Imamura J, et al. Mutations of p53 in Wilms' tumors. Mod Pathol. 1995;8(5):483-7.

42. Malkin D, Sexsmith E, Yeger H, Williams BR, Coppes MJ. Mutations of the p53 tumor suppressor gene occur infrequently in Wilms' tumor. Cancer Res. 1994;54(8):2077-9.

43. Beniers AJ, Efferth T, Fuzesi L, Granzen B, Mertens R, Jakse G. p53 expression in Wilms' tumor: a possible role as prognostic factor. Int J Oncol. 2001;18(1):133-9.

44. Javelaud D, Mauviel A. Mammalian transforming growth factor-betas: Smad signaling and physio-pathological roles. Int J Biochem Cell Biol. 2004;36(7):1161-5.

45. Zhang L, Liu W, Qin Y, Wu R. Expression of TGF-beta1 in Wilms' tumor was associated with invasiveness and disease progression: J Pediatr Urol. 2014;10(5)962-8

\section{Submit your next manuscript to BioMed Central and take full advantage of:}

- Convenient online submission

- Thorough peer review

- No space constraints or color figure charges

- Immediate publication on acceptance

- Inclusion in PubMed, CAS, Scopus and Google Scholar

- Research which is freely available for redistribution 